\title{
Platelet-Derived Growth Factor-AA and - $\alpha$ Receptor Expression Suggests an Autocrine and/or Paracrine Loop in Osteosarcoma
}

\author{
Irene Sulzbacher, M.D., Margit Träxler, Isabella Mosberger, Susanna Lang, M.D., Andreas Chott, M.D. \\ Department of Clinical Pathology, University of Vienna Medical School, Vienna, Austria
}

Platelet-derived growth factor (PDGF) is a major mitogen and chemotactic factor for mesenchymal cells such as fibroblasts, smooth muscle cells, and osteoblasts. PDGF exists as disulfide-linked homoor heterodimers composed of two polypeptide chains encoded by distinct genes, designated PDGF-A and PDGF-B. Upon binding to its tyrosine kinase receptor PDGF- $\alpha$, especially PDGF-AA stimulates the proliferation of osteoblastic cells and may exert autocrine and paracrine effects in regulating bone-forming processes. The purpose of this immunohistochemical study was to determine the expression of PDGF-AA and PDGF- $\alpha$ receptor in benign and malignant neoplastic bone lesions. Polyclonal antibodies to PDGF-AA and PDGF- $\alpha$ receptor were used on paraffin sections of 23 osteosarcomas and 17 osteoblastomas. Immunostaining was assessed quantitatively by evaluating the percentage of reactive tumor cells. In osteosarcomas, the mean expression of PDGF-AA and PDGF- $\alpha$ receptor was $33.97 \%$ (range, 2 to $80 \%$; SD, $24.26 \%$ ) and $27.13 \%$ (range, 3.2 to $72 \%$; $\mathrm{SD}, 18.38 \%$ ), respectively. Osteoblastomas showed significantly lower expression of PDGF-AA than osteosarcomas (mean, 15.71\%; range, 5 to $34 \%$; $S D, 9.43 \% ; P=.019)$. Although the mean expression of PDGF- $\alpha$ receptor in osteoblastomas was much lower than in osteosarcomas (mean, $17.55 \%$; range, 3.6 to $26.8 \%$; $S D, 6.47 \%$ ), the difference was not significant $(P=.122)$. For osteosarcomas, Spearman correlation coefficient (twotailed) revealed a significant correlation between the expression of PDGF-AA and PDGF- $\alpha$ receptor $(r=.688)$, which was not the case for osteoblastomas $(r=.267)$. These data suggest that in contrast to osteoblastoma, the growth of osteosarcoma may be supported by the coordinate expression of the po-

Copyright (C) 2000 by The United States and Canadian Academy of Pathology, Inc.

VOL. 13, NO. 6, P. 632, 2000 Printed in the U.S.A.

Date of acceptance: December 7, 1999.

Address reprint requests to: Irene Sulzbacher, M.D., Department of Clinical Pathology, Vienna General Hospital, Währinger Gürtel 18-20, A-1090 Vienna, Austria; fax: 43-1-4053402. tent mitogenic growth factor and its receptor that exert their functions by autocrine and paracrine mechanisms.

KEY WORDS: Osteoblastoma, Osteosarcoma, Platelet-derived growth factor AA, Platelet-derived growth factor $\alpha$ receptor.

Mod Pathol 2000;13(6):632-637

The platelet-derived growth factors (PDGFs) are encoded by two independently regulated genes, PDGF-A and PDGF-B, located on chromosomes 22 and 7 , respectively (1). The two genes encode for distinct polypeptide chains, which exhibit approximately $56 \%$ sequence homology and can combine to form three disulfide-linked dimers $\mathrm{AA}, \mathrm{BB}$, or $\mathrm{AB}$. After ligand binding, the PDGF receptor dimerizes into homodimers $(\alpha \alpha$ or $\beta \beta$ ) or the heterodimer $\alpha \beta$. PDGF-AA binds to the $\alpha \alpha$ receptor, whereas PDGF-AB binds to the $\alpha \alpha$ or $\alpha \beta$ receptors and PDGF-BB binds to all three receptors (2). These growth factors are produced and secreted by megakaryocytes, activated vascular endothelial cells, macrophages, fibroblasts, and smooth muscle cells $(3,4)$. Cells of mesenchymal origin, such as chondrocytes, are the target of PDGFs, in which they stimulate proliferation and differentiation (5). Recent studies have focused on the expression of PDGF-AA and PDGF- $\alpha$ receptor in bone fractures (6) and heterotopic and osteophytic bone (7). In osteoblasts, PDGF-AA mRNA expression has been demonstrated by in situ hybridization in all stages of activity, whereas the PDGF-BB mRNA was restricted to active osteoblasts adjacent to woven bony trabeculae (6). Expression of PDGF-AA and PDGF- $\alpha$ receptor has been shown in rapidly forming human bone by immunohistochemistry (7). Experimental studies using cultured rat osteoblasts have demonstrated increased expression of PDGF-A mRNA after treatment with PDGF-AA or PDGF-BB (8).

Little is known about the involvement of these growth factors in benign and malignant neoplastic 
bone lesions, and up to now these investigations were largely restricted to in vitro studies. In osteosarcoma cell lines, tumor cells may stimulate their proliferation through an autocrine mechanism by simultaneously producing growth factors and growth factor receptors $(9,10)$. In human osteosarcomas, expression of both PDGF and receptor has been demonstrated in $38 \%$ of the cases (11). Similarly, epithelial tumors, such as prostate adenocarcinoma (12) and invasive breast cancer (13), have been shown to coexpress PDGF-AA and PDGF- $\alpha$ receptor, suggesting an autocrine mechanism of cell proliferation control.

The purpose of this study was to examine the expression of PDGF-AA and PDGF- $\alpha$ receptor in a series of malignant and benign human bone tumors (i.e., osteosarcomas and osteoblastomas) and to find out whether there is a correlation between ligand and receptor expression. The majority of osteosarcomas and osteoblastomas showed expression of PDGF-AA and PDGF- $\alpha$ receptor in a significant proportion of tumor cells. Osteosarcomas differed from osteoblastomas by higher proportion of PDGF-AA and PDGF- $\alpha$ receptor-positive tumor cells and by the statistically significant correlation between PDGF-AA and PDGF- $\alpha$ receptor expression, suggestive of an autocrine loop that could represent a mechanism contributing to osteosarcoma growth.

\section{MATERIALS AND METHODS}

\section{Tissue}

The retrospective study comprised diagnostic pretreatment biopsies of 23 osteosarcomas and 17 cases of osteoblastoma resection specimens. The tissue was fixed in $7.5 \%$ buffered formalin ( $\mathrm{pH} 7.4$ ), decalcified with EDTA, and routinely processed. The osteosarcomas consisted of 20 intramedullary high-grade tumors and three low-grade osteosarcomas ( 1 central, 2 parosteal). The tumors were classified according to histologic type and differentiation $(14,15)$, as shown in Table 1.

Bone lesions with increased remodeling sites were used as controls and comprised one specimen each diagnosed as arthrosis, pseudoarthrosis, osteomyelitis, callus formation, and osteoblastic adenocarcinoma metastasis.

\section{Immunohistochemistry}

Serial sections were used for immunohistochemical staining for PDGF-AA and PDGF- $\alpha$ receptor, respectively, and corresponding sections were stained with hematoxylin and eosin. Immunohistochemical studies were done on paraffin sections using a polyclonal antibody against human
TABLE 1. Expression of PDGF-AA and PDFG- $\alpha$ Receptor in Osteosarcoma

\begin{tabular}{lcccc}
\hline Case & Type & Grade & $\begin{array}{c}\text { PDGF-AA } \\
(\%)\end{array}$ & $\begin{array}{c}\text { PDGF- } \alpha \\
\text { Receptor }(\%)\end{array}$ \\
\hline 1 & m & hg & 2 & 23.1 \\
2 & o & hg & 20.6 & 10 \\
3 & o & hg & 64 & 65.6 \\
4 & m & hg & 80 & 18.2 \\
5 & o & hg & 64.1 & 31.4 \\
6 & o & hg & 41.9 & 44.5 \\
7 & o & hg & 36.9 & 11.6 \\
8 & o & hg & 20.8 & 30 \\
9 & o & hg & 41.9 & 35.4 \\
10 & o & hg & 80 & 38 \\
11 & c & hg & 8.6 & 6.8 \\
12 & o & hg & 19.1 & 23.7 \\
13 & o & hg & 51.6 & 52 \\
14 & o & hg & 27 & 18 \\
15 & o & hg & 15.5 & 28.8 \\
16 & o & hg & 41.7 & 24.7 \\
17 & o & hg & 40 & 37 \\
18 & o & hg & 66.7 & 72 \\
19 & o & hg & 16 & 20 \\
20 & p & lg & 21.5 & 14.2 \\
21 & p & lg & 11.3 & 3.2 \\
22 & t & hg & 6.2 & 4.8 \\
23 & clg & lg & 4 & \\
\hline
\end{tabular}

PDGF, platelet-derived growth factor; o, osteoblastic; c, chondroblastic; m, mixed; t, telangiectatic; clg, central low grade; p, parosteal; hg, high grade; lg, low grade.

PDGF-AA (N-30, Santa Cruz Biotechnology, Santa Cruz, CA; $1: 50$ ) raised against a peptide corresponding to amino acids 182-211. After incubation at room temperature for $1 \mathrm{~h}$, the secondary biotinylated goat antirabbit IgG antibody (1:100) was applied for 30 min followed by incubation with the avidin-biotin complex with alkaline phosphatase (ABC-AP Kit, Vector Laboratories Burlingame, CA). The reaction was developed in the presence of fast red chromogen system (Coulter Immunotech, Marseille, France). The antibody used for the detection of PDGF- $\alpha$ receptor (C-20; Santa Cruz Biotechnology; 1:40) was a rabbit polyclonal antibody raised against a peptide corresponding to amino acids 1065-1084 mapping within the carboxy terminal domain of PDGF- $\alpha$ receptor. Sections were pretreated by microwaving in citrate buffer $(\mathrm{pH}$ 6.0) twice for $5 \mathrm{~min}$ each at $600 \mathrm{~W}$. The sections were incubated with the antibody for $1 \mathrm{~h}$ followed by incubation with biotinylated goat antirabbit IgG as a secondary antibody (1:100) and then alkaline phosphatase-conjugated streptavidin (Super Sensitive HRP Label; Biogenex, San Ramon, CA). The reaction was visualized by new fuchsin (Dako, Carpinteria, CA) as a chromogen. For both antibodies, nonspecific reactivity was assessed by omission of the primary antibody and the specificity of staining was confirmed in tumor sections as well as in control tissue by preabsorption of the antisera with blocking peptides supplied by the manufacturer.

Equimolar concentrations of antibody and blocking peptides were incubated in $1 \%$ Tris-phosphate- 
buffered saline for $1 \mathrm{~h}$ at room temperature. Staining for PDGF-AA and for PDGF- $\alpha$ receptor was completely abolished by this procedure.

Immunoreactivity was assessed at high-power magnification in 5 to 8 microscopic fields that showed maximum reactivity and was expressed as the percentage of positive cells per 500 tumor cells. Staining intensity was not taken into account as it varied considerably from case to case and even in the same section. In addition, staining intensity might be influenced by the varying duration of fixation and different age of the paraffin blocks. Fresh tissue for quantitative molecular and functional studies was not available.

\section{Statistical Analyses}

To evaluate the correlation between the expression of PDGF-AA and PDGF- $\alpha$ receptor, Spearman rank correlation test was used. Mann-Whitney $U$ test was used as a nonparametric univariate analysis to compare the percentages of tumor cells that were reactive to PDGF-AA and PDGF- $\alpha$ receptor in osteosarcomas versus osteoblastomas. $P$ values less than .05 were considered significant. All statistical analyses were performed using SPSS software (RE 8.0; SPSS, Inc., Chicago, IL).

\section{RESULTS}

\section{PDGF-AA and PDGF- $\alpha$ Receptor Expression in Control Tissues}

In the control material (arthrosis, pseudoarthrosis, osteomyelitis, callus formation, and osteoblastic adenocarcinoma metastasis), activated cuboidal osteoblasts stained strongly for PDGF-AA and PDGF- $\alpha$ receptor and even quiescent osteoblasts flattening out as lining cells on the surface of bony trabeculae showed weak staining (Fig. 1A, B). Osteoclasts expressed PDGF-AA, and sometimes weak reactivity to PDGF- $\alpha$ receptor antibody was found. Occasional osteocytes stained for PDGF-AA, whereas PDGF- $\alpha$ receptor was negative in these cells. These findings are consistent with a previous report except for the weak reactivity for PDGF- $\alpha$ receptor observed in osteoclasts (7).

\section{PDGF-AA and PDGF- $\alpha$ Receptor Expression in Osteosarcoma}

Reactivity to both antibodies was observed in all 23 osteosarcomas (Table 1); however, staining intensity was heterogeneous, varying widely from one microscopic field to another (Fig. 1C, D). PDGF-AA was not restricted to any kind of tumor cell type but was seen in osteoblastic cells as well as in pleomorphic tumor elements. In serial sections, coexpression of both proteins in the same cell was widely detectable, although some tumor elements showed only positivity for one antibody. The mean expression of PDGF-AA and PDGF- $\alpha$ receptor was $33.97 \%$ (range, 2 to $80 \%$; SD, 24.26\%) and $27.13 \%$ (range, 3.2 to $72 \%$; $\mathrm{SD}, 18.38 \%$ ), respectively. It is interesting that in comparison to the high-grade tumors, the three low-grade osteosarcomas gave relatively low percentage values for both proteins. The lowest values overall were obtained from the central lowgrade osteosarcoma (Table 1).

\section{PDGF-AA and PDGF- $\alpha$ Receptor Expression in Osteoblastoma}

Osteoblastomas showed significantly lower expression of PDGF-AA than osteosarcomas (mean, $15.71 \%$; range, 5 to $34 \%$; SD, $9.43 \% ; P=.019$ ). Although the mean expression of PDGF- $\alpha$ receptor in osteoblastomas was much lower than in osteosarcomas (mean, $17.55 \%$; range, 3.6 to $26.8 \%$; SD, $6.47 \%)$, the difference was not significant $(P=.122)$. On serial sections, some tumor osteoblasts showed positivity for both antibodies (Fig. 1E, F). The mononuclear cells between the bony trabeculae were partially positive, and even osteoclasts strongly expressed PDGF-AA. Labeling of osteoclasts for PDGF- $\alpha$ receptor was only focally detectable and of much weaker intensity (Table 2).

For osteosarcomas, Spearman correlation coefficient (two-tailed) revealed a significant correlation between the expression of PDGF-AA and PDGF- $\alpha$ receptor $(r=.688)$, which was not the case for osteoblastomas ( $r=.267$ ) (Fig. 2A, B).

\section{DISCUSSION}

PGDF has potent effects on mesenchymal tissue cells. The growth factor is made up of dimers of A and $\mathrm{B}$ polypeptide chains, which are combined to generate the three isoforms of PDGF (AA, BB, AB). Binding to its respective receptor triggers a cascade of events that include receptor autophosphorylation, phosphorylation of intracellular substrates, and activation of signaling pathways involved in metabolic processes and enhanced cell proliferation. The role of the different PDGF isoforms in bone cells is not clearly defined, but it is established that osteoblasts produce and respond to PDGF-AA (16-18), indicating that PDGF-AA may function in an autocrine manner to regulate bone formation. PDGF-AA can also be detected in all stages of fracture healing, making it the predominant isoform in this situation (6).

The expression of PDGF-AA and its receptor in neoplastic osteoblasts has hardly been examined. The few published studies were mainly limited to the use of osteosarcoma cell lines $(9,19)$ with the exception of a series on 37 osteosarcomas in which 


\section{PDGF-AA}
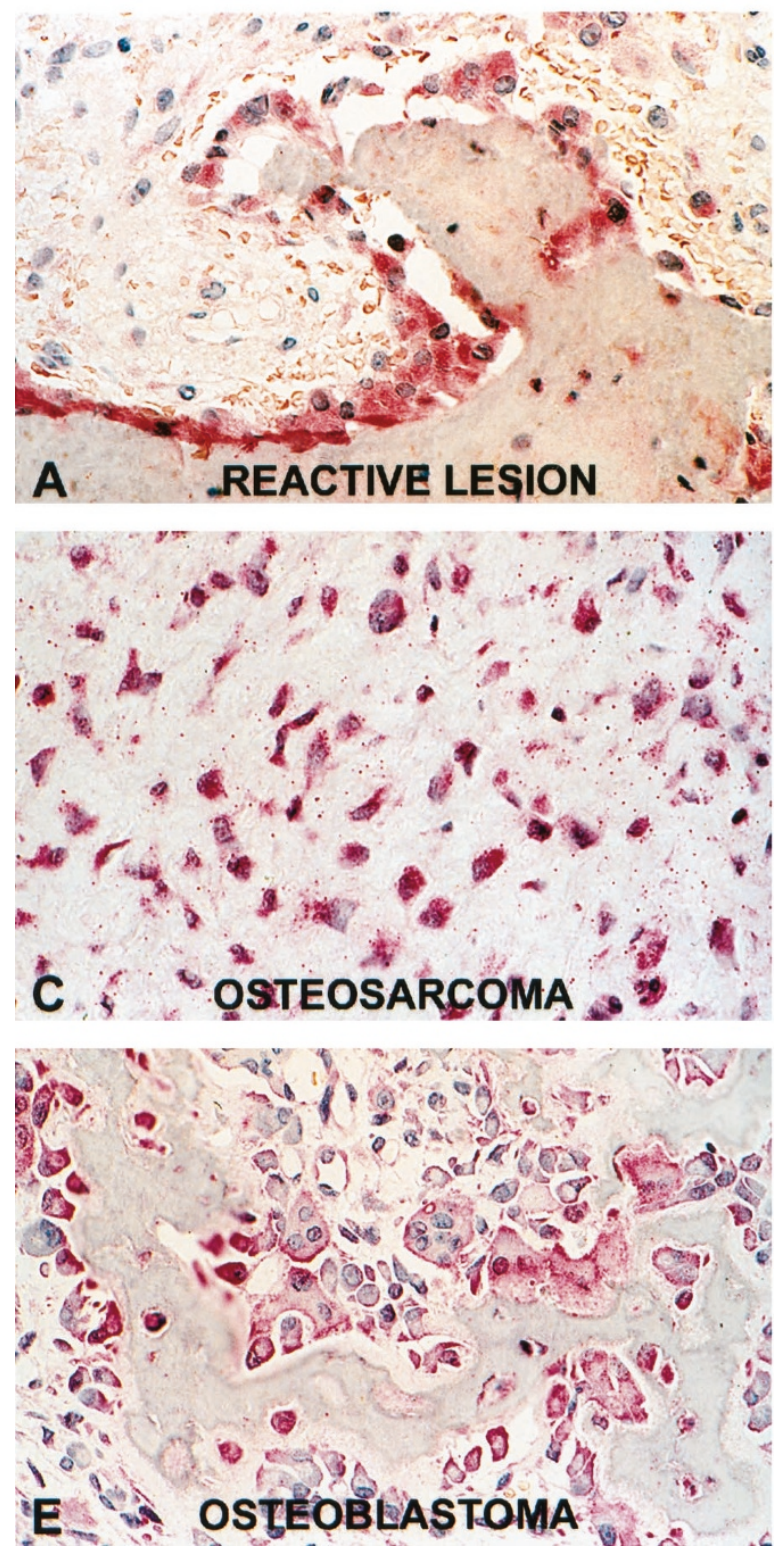

PDGF- $\alpha$ Receptor
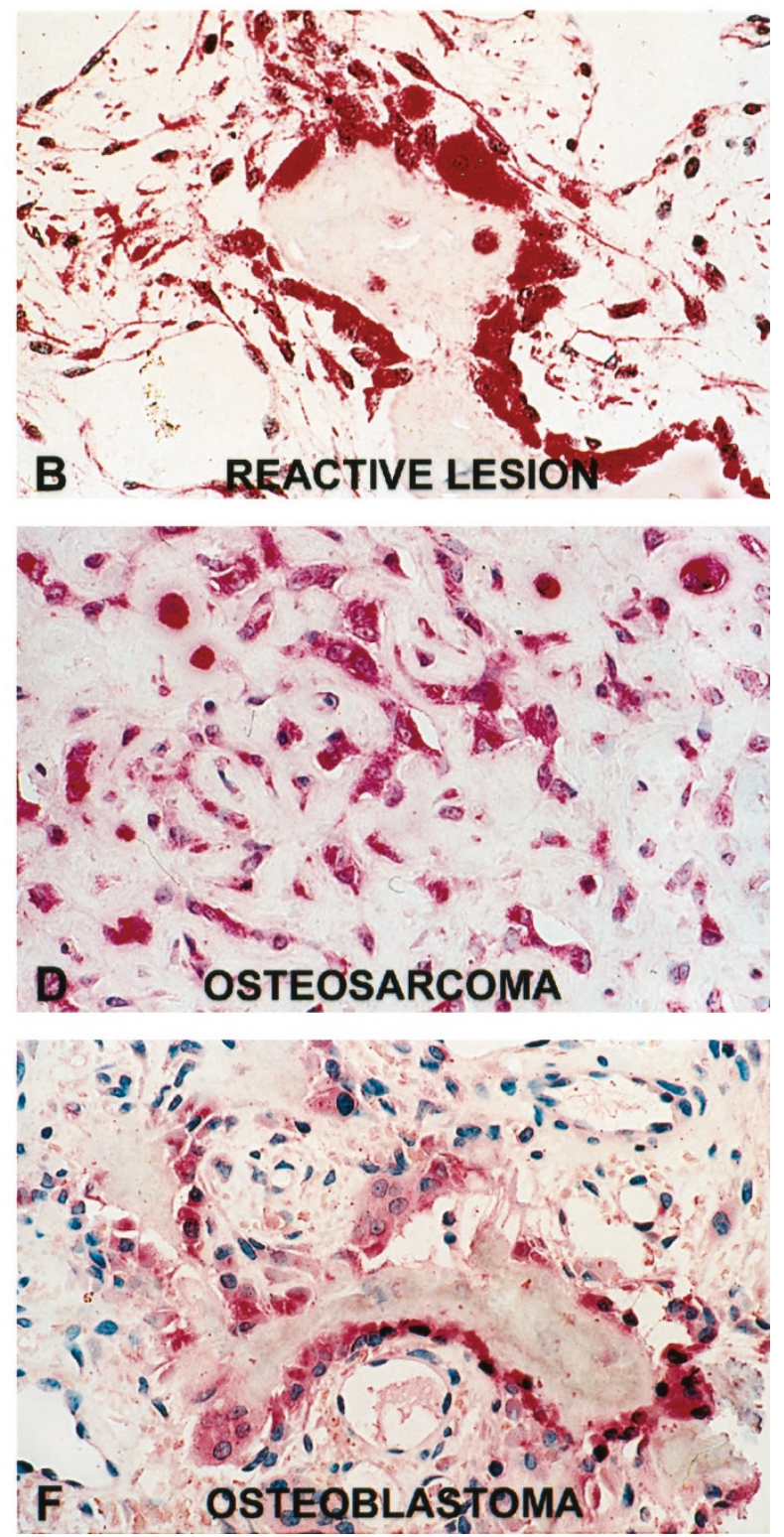

FIGURE 1. Immunohistochemical staining for platelet-derived growth factor AA (left panel) and platelet-derived growth factor $\alpha$ receptor (right panel) in representative example of reactive lesion (A, B), chondroblastic osteosarcoma (C, D), and osteoblastoma (E, F),

the PDGF antibody used did not differentiate between the PDGF isoforms, and the correlation between the expression of factor and receptor has not been examined (11).

In this study, we addressed the question of whether there are different expression levels of PDGF-AA and PDGF- $\alpha$ receptor in benign versus malignant bone tumors and we therefore examined a series of 17 human osteoblastomas and 23 human osteosarcomas by immunohistochemistry on paraffin sections. Not only did osteosarcomas show higher levels of PDGF-AA and PDGF- $\alpha$ receptor, but also there was a significant correlation between the expression of ligand and receptor. Although immunohistochemical positivity is not absolute proof of a functional role, the abundance of expression in combination with the spatial relationship demonstrated on serial sections suggests an autocrine loop in osteosarcoma, which may contribute to tumor growth and progression. Further functional studies on the protein and mRNA level are needed to confirm the findings of this study and to determine whether ligand and receptor are overexpressed in osteosarcoma.

Growth and progression of solid tumors are dependant on neovascularization, a process in which the angiogenic factor vascular endothelial growth factor is essential (20). Expression of vascular endothelial growth factor has recently been reported to occur in osteosarcomas (21), and its expression is 
TABLE 2. Expression of PDGF-AA and PDGF- $\alpha$ Receptor in Osteoblastoma

\begin{tabular}{lcc}
\hline Case & $\begin{array}{c}\text { PDGF-AA } \\
(\%)\end{array}$ & $\begin{array}{c}\text { PDGF- } \alpha \\
\text { Receptor } \\
(\%)\end{array}$ \\
\hline 1 & 7.3 & 9.4 \\
2 & 28.2 & 21.5 \\
3 & 34 & 13.4 \\
4 & 11.1 & 18.8 \\
5 & 26.9 & 20 \\
6 & 5 & 23.7 \\
7 & 6.5 & 3.6 \\
8 & 20.4 & 19.8 \\
9 & 5.7 & 14.9 \\
10 & 20.3 & 26.8 \\
11 & 6.7 & 14.2 \\
12 & 11 & 21 \\
13 & 5.3 & 15.8 \\
14 & 11.2 & 19.4 \\
15 & 20.9 & 7.2 \\
16 & 23.7 & 24.9 \\
17 & 22.9 & 24.1 \\
\hline
\end{tabular}

PDGF, platelet-derived growth factor.
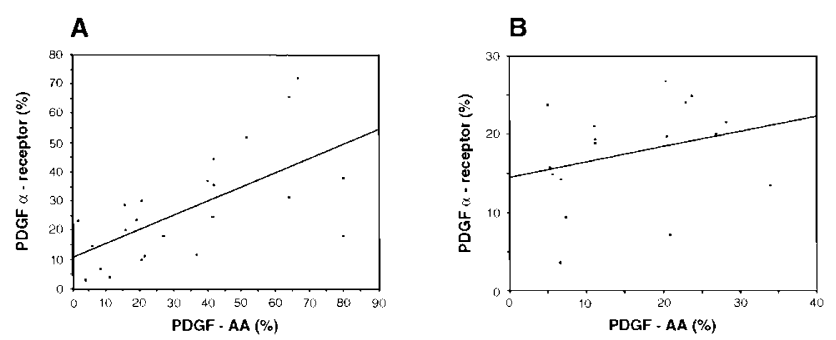

FIGURE 2. Correlation of platelet-derived growth factor AA and platelet-derived growth factor $\alpha$ receptor expression in osteosarcoma (A) and osteoblastoma (B).

positively influenced by the inducing agents PDGF and transforming growth factors $\alpha$ and $\beta$ (22). The coordinate expression of PDGF-AA and PDGF- $\alpha$ receptor demonstrated herein and the expression of transforming growth factor $\beta$ and receptor published elsewhere $(23,24)$ suggest that these two factors may influence growth and progression in osteosarcoma in part by stimulating angiogenesis.

Insulin-like growth factors (IGF-I, IGF-II) have similarly been implicated in growth promotion of tumors in vivo and in vitro. Expression of both IGF-I and IGF-II receptors has been found in osteosarcoma cells and synthesis of IGF-II induced autocrine growth stimulation via the IGF-I receptor (25).

To summarize, we provide evidence of PDGF-AA and PDGF- $\alpha$ receptor expression in osteosarcoma and osteoblastoma. Comparison between the two tumor categories revealed that PDGF-AA is significantly increased in osteosarcoma and that it significantly correlates with the expression of its receptor, which is not the case in osteoblastoma. These data suggest that in contrast to osteoblastoma, the growth of osteosarcoma may be supported by the coordinate expression of the potent mitogenic growth factor and its receptor that exert their function by autocrine and/or paracrine mechanisms.

\section{REFERENCES}

1. Westermark B, Heldin CH. Platelet-derived growth factor. Acta Oncol 1993;32:101-5.

2. Seifert RA, Hart CE, Phillips PE, Forstrom JW, Ross R, Murray $\mathrm{MJ}$, et al. Two different subunits associate to create isoformspecific platelet-derived growth factor receptors. J Biol Chem 1989;264:8771-8.

3. Libby P, Warner SJ, Salomon RN, Birinyi LK. Production of platelet-derived growth factor-like mitogen by smoothmuscle cells from human atheroma. N Engl J Med 1988;318: 1493-8.

4. Ross R. Platelet-derived growth factor. Lancet 1989;1:117982.

5. Guerne PA, Blanco F, Kaelin A, Desgeorges A, Lotz M. Growth factor responsiveness of human articular chondrocytes in aging and development. Arthritis Rheum 1995;38: 960-8.

6. Andrew JG, Hoyland JA, Freemont AJ, Marsh DR. Plateletderived growth factor expression in normally healing human fractures. Bone 1995;16(4):455-60.

7. Horner A, Bord S, Kemp P, Grainger D, Compston JE. Distribution of platelet-derived growth factor (PDGF): a chain mRNA, protein, and PDGF-alpha receptor in rapidly forming human bone. Bone 1996;19(4):353-62 .

8. Rydziel S, Shaikh S, Canalis E. Platelet-derived growth factor-AA and -BB (PDGF-AA and -BB) enhance the synthesis of PDGF-AA in bone cell cultures. Endocrinology 1994; 134:2541-6.

9. Harsh GH, Keating MT, Escobedo JA, Williams LT. Plateletderived growth factor (PDGF) autocrine components in human tumor cell lines. J Neurooncol 1990;8:1-12.

10. Graves DT, Valentin-Opran A, Delgado R, Valente AJ, Mundy G, Piche J. The potential role of platelet-derived growth factor as an autocrine or paracrine factor for human bone cells. Connect Tissue Res 1989;23:209-18.

11. Oda Y, Wehrmann B, Radig K, Walter H, Rose I, Neumann W, et al. Expression of growth factors and their receptors in human osteosarcomas. Immunohistochemical detection of epidermal growth factor, platelet-derived growth factor and their receptors: its correlation with proliferating activities and p53 expression. Gen Diagn Pathol 1995;141:97-103.

12. Fudge K, Wang CY, Stearns ME. Immunohistochemistry analysis of platelet-derived growth factor $\mathrm{A}$ and $\mathrm{B}$ chains and platelet-derived growth factor $\alpha$ and $\beta$ receptor expression in benign prostate hyperplasias and Gleason-graded human prostate adenocarcinomas. Mod Pathol 1994;7:549-54.

13. De Jong JS, Van Diest PJ, Van der Valk P, Baak JPA. Expression of growth factors, growth inhibiting factors, and their receptors in invasive breast cancer: I. An inventory in search of autocrine and paracrine loops. J Pathol 1998;184:44-52.

14. Mirra JM, Gold RH, Picci P. Osseous tumors of intramedullary origin. In: Mirra JM, editor. Bone tumors: diagnosis, treatment and prognosis, 1st ed. Vol 1. Philadelphia: Lea \& Febiger; 1989. p. 143-438.

15. Unni KK. Osteosarcoma. In. Unni KK, editor. Dahlin's bone tumors general aspects and data on 11,087 cases. 5th ed. Philadelphia: Lippincott-Raven; 1996. p. 143-83.

16. Rydziel S, Ladd C, McCarthy TL, Centrella M, Canalis E. Determination and expression of platelet-derived growth factor-AA in bone cell cultures. Endocrinology 1992;130:1916-22.

17. Sato N, Beitz JG, Kato J, Yamamoto M, Clark JW, Calabresi P, 
et al. Platelet-derived growth factor indirectly stimulates angiogenesis in vitro. Am J Pathol 1993;142:1119-30.

18. Zhang L, Leeman E, Carnes DC, Graves DT. Human osteoblasts synthesize and respond to platelet-derived growth factor. Am J Physiol 1991;261:C348-54.

19. Betsholtz C, Westermark B, Ek B, Heldin CH. Coexpression of a PDGF-like growth factor and PDGF receptors in a human osteosarcoma cell line: implications for autocrine receptor activation. Cell 1984;39:447-57.

20. Folkman J. Angiogenesis in cancer, vascular, rheumatoid and other disease. Nat Med 1995;1:27-31.

21. Lee YH, Tokunaga T, Oshika Y, Suto R, Yanagisawa K, Tomisawa $\mathrm{M}$, et al. Cell-retained isoforms of vascular endothelial growth factor (VEGF) are correlated with poor prognosis in osteosarcoma. Eur J Cancer 1999;35:1089-93.

22. Dvorak HF, Brown LF, Detmar M, Dvorak AM. Vascular permeability factor/vascular endothelial growth factor, mi- crovascular permeability, and angiogenesis. Am J Pathol 1995;146:1029-39.

23. Kloen P, Gebhardt MC, Perez-Atayde A, Rosenberg AE, Springfield DS, Gold LI, et al. Expression of transforming growth factor- $\beta$ (TGF- $\beta$ ) isoforms in osteosarcomas. Cancer 1997;80:2230-9.

24. Kloen P, Jennings CL, Gebhardt MC, Springfield DS, Mankin HJ. Expression of transforming growth factor-beta (TGFbeta) receptors, TGF-beta 1 and TGF-beta 2 production and autocrine growth control in osteosarcoma cells. Int J Cancer 1994;58(3):440-5.

25. Raile K, Hoflich A, Kessler U, Yang Y, Pfuender M, Blum WF, et al. Human osteosarcoma (U-2 OS) cells express both insulin-like growth factor (IGF-I) receptors and insulin-like growth factor-II/mannose-6-phosphate (IGF-II/M6P) receptors and synthesize IGF-II: autocrine growth stimulation by IGF-II via the IGF-I receptor. J Cell Physiol 1994;159:531-41.

\section{Book Review}

\section{Damjanov I, Rubin E: Review of Pathology, 2nd Ed, 250 pp, Baltimore, Lippincott Williams \& Wilkins, 2000 (\$26.50).}

There are several published study guides that concentrate on the core concepts of pathology through questions, answers, and brief explanations. The second edition of these distinguished authors' text is similar, but the format has been modified by concentrating on more clinically relevant material and by using questions that conform to the National Board of Medical Examiners (NBME).

More than 1000 questions in this textbook cover both general and systemic pathology, with approximately one half using clinical vignettes that emphasize clinicopathologically relevant features of different concepts and disease processes. The authors claim that the book concentrates on "high-yield" topics (with each question covering more than one topic) that consistently recur on the USMLE-1 examinations, with which I concur. The questions follow NBME format by using simple best-answer multiple-choice questions or extended multiple-choice questions (with more than five choices from which to select). True-false questions or " $K$ " type questions are no longer used. Several of the questions in the main text use images and graphs in the stem. Each question also includes a brief explanation of the correct answer at the end of the chapter.

At the end of the book is a comprehensive examination that includes 125 questions, 24 of which contain color images and brief explanations of the answers. The authors supply a grading scale that a student may use to predict success on his or her medical school's final examination or on the USMLE-1.

My only recommendation of this review text for future editions is to increase the already prominent number of clinically relevant questions and to use more images with questions containing clinical vignettes. This review book certainly provides sophomore medical students with a supplement to learning clinically relevant information of pathology in preparation for their clinical years in medical school. Students are always requesting old test questions or sample exams to use during a pathology course or for preparing for the USMLE-1. Faculty members who teach often request "question writing" advice; they will also find this book beneficial as a guideline. This text certainly meets the needs of these students and teaching faculty and is highly recommended for medical students who are taking pathology, for those who are preparing for the USMLE-1, and for medical school faculty members who are directing or teaching in a pathology course.

\section{Byron E. Crawford \\ Tulane University School of Medicine New Orleans, Louisiana}

